ERRATUM

Z. Asghar · D. Yau - F. Chan - D. LeRoith

C. B. Chan - M. B. Wheeler

\title{
Insulin resistance causes increased beta-cell mass but defective glucose-stimulated insulin secretion in a murine model of type 2 diabetes
}

Published online: 9 February 2006

(C) Springer-Verlag 2006

The online version of the original article can be found at http://dx. doi.org/10.1007/s00125-005-0045-y

Z. Asghar · D. Yau · F. Chan · M. B. Wheeler $(\bowtie)$

Department of Physiology, University of Toronto,

1 King's College Circle Room 3352,

Toronto, ON, Canada, M5S 1A8

e-mail: michael.wheeler@utoronto.ca

Tel.: +1-416-9786737

Fax: $+1-416-9784940$

M. B. Wheeler

Department of Medicine, University of Toronto,

Toronto, ON, Canada

D. LeRoith

Diabetes Branch, National Institute of Diabetes

and Digestive and Kidney Diseases (NIDDK),

National Institutes of Health,

Bethesda, MD, USA

C. B. Chan

Department of Biomedical Sciences,

Atlantic Veterinary College,

University of Prince Edward Island,

Charlottetown, PE, Canada
In the online version of this paper (DOI/10.1007/s00125005-0045-y) it was stated that Asghar and Chan contributed equally to this work. The sentence should have read:

Asghar and Yau contributed equally to this work. 